\title{
Energy system contribution during 200- to $1500-m$ running in highly trained athletes
}

\author{
MATT R. SPENCER and PAUL B. GASTIN
}

Human Performance Laboratory, Department of Human Movement and Sport Sciences, University of Ballarat, Ballarat, Victoria, AUSTRALIA; and Victorian Institute of Sport, Melbourne, Victoria, AUSTRALIA

\begin{abstract}
SPENCER, M. R., and P. B. GASTIN. Energy system contribution during 200- to 1500-m running in highly trained athletes. Med. Sci. Sports Exerc., Vol. 33, No. 1, 2001, pp. 157-162. Purpose: The purpose of the present study was to profile the aerobic and anaerobic energy system contribution during high-speed treadmill exercise that simulated 200-, 400-, 800-, and 1500-m track running events. Methods: Twenty highly trained athletes (Australian National Standard) participated in the study, specializing in either the 200-m $(N=3), 400-\mathrm{m}(N=6), 800-\mathrm{m}(N=5)$, or $1500-\mathrm{m}(N=6)$ event $\left(\right.$ mean $\dot{\mathrm{VO}} 2$ peak $\left[\mathrm{mL}^{\mathrm{k}} \mathrm{kg}^{-1} \cdot \mathrm{min}^{-1}\right] \pm \mathrm{SD}=56 \pm 2,59 \pm 1$, $67 \pm 1$, and $72 \pm 2$, respectively). The relative aerobic and anaerobic energy system contribution was calculated using the accumulated oxygen deficit (AOD) method. Results: The relative contribution of the aerobic energy system to the 200-, 400-, 800-, and 1500-m events was $29 \pm 4,43 \pm 1,66 \pm 2$, and $84 \pm 1 \% \pm \mathrm{SD}$, respectively. The size of the AOD increased with event duration during the 200-, 400-, and 800-m events (30.4 $\pm 2.3,41.3 \pm 1.0$, and $48.1 \pm 4.5 \mathrm{~mL} \cdot \mathrm{kg}^{-1}$, respectively), but no further increase was seen in the $1500-\mathrm{m}$ event $\left(47.1 \pm 3.8 \mathrm{~mL} \cdot \mathrm{kg}^{-1}\right)$. The crossover to predominantly aerobic energy system supply occurred between 15 and $30 \mathrm{~s}$ for the 400-, 800-, and 1500-m events. Conclusions: These results suggest that the relative contribution of the aerobic energy system during track running events is considerable and greater than traditionally thought. Key Words: MAXIMAL ACCUMULATED OXYGEN DEFICIT, OXYGEN DEMAND, ANAEROBIC CAPACITY, SUBMAXIMAL, SUPRAMAXIMAL
\end{abstract}

$\mathrm{S}$ pecificity of training is perhaps the most significant principle used in athlete preparation. Evaluation of event or sport requirements therefore precedes both training planning and implementation. Energy supply is usually critical such that the relative contribution of the aerobic and anaerobic energy systems becomes an important factor. Little data exist that specifically and accurately evaluate energy system contributions in discrete sporting events. Considerable information can be found that attempts to do so $(15,16)$, but this has generally been based on data originating in the 1970s that inappropriately used oxygen debt to quantify anaerobic energy release.

The use of the accumulated oxygen deficit method popularised by Medbø et al. (21) has enabled a number of researchers to report relative energy system contributions for exhaustive exercise over varying durations $(8,22,29)$. These and other studies employed either all-out exercise over a given time period or constant intensity exercise, usually at a percentage of maximal oxygen uptake, until exhaustion. Few studies have set out to simulate a specific cycling or running event. Most events are staged over set distances, with velocity usually being dependent on individual energetic rates and capacities. Although extrapolations from available data in the literature have appeared $(5,6)$, few direct event analyses exist. Data from these stud-

0195-9131/01/3301-0157/\$3.00/0

MEDICINE \& SCIENCE IN SPORTS \& EXERCISE ${ }_{\circledast}$

Copyright (C) 2001 by the American College of Sports Medicine

Received for publication January 2000.

Accepted for publication May 2000. ies suggest considerably greater aerobic energy system contributions than have previously been presented.

Given the paucity of data relating to energy system contributions to sporting events and the need to reevaluate traditional information presented in the literature, the present study was designed to profile the aerobic and anaerobic energy system response during high-speed treadmill exercise that simulated 200-, 400-, 800-, and 1500-m track running events.

\section{METHODS}

Subjects. Four independent subject groups were used for this study. The sample population was restricted to highly trained athletes of the selected running events of 200-m $(N=3), 400-\mathrm{m}(N=6), 800-\mathrm{m}(N=5)$ and 1500-m $(N=6)$. The athletes who participated in the study were all male and competed at a state, national, and in some cases international level (Table 1). The personal best times of the athletes suggested they were of good to high quality. Five of the 20 subjects had represented Australia at either junior or open international competition. All athletes were tested either during or immediately after completion of the competition phase of their yearly program; most cases being post Australian National Championships. Before participation, subjects were given a written explanation of the time commitments and testing procedures involved in the study. The University of Ballarat Experimentation Ethics Committee cleared all testing procedures, and subjects were given both written and verbal explanations before signing a declaration of informed consent. 


\begin{tabular}{|c|c|c|c|c|}
\hline & Age (yr) & $\begin{array}{l}\text { Weight } \\
\text { (kg) }\end{array}$ & $\begin{array}{l}\text { Peak } \mathrm{O}_{2} \text { Uptake } \\
\left(\mathrm{mL} \cdot \mathrm{kg}^{-1} \cdot \mathrm{min}^{-1}\right)\end{array}$ & $\begin{array}{c}\text { Personal Best } \\
\text { Time (min:s) }\end{array}$ \\
\hline Mean $\pm S D$ & $19 \pm 4$ & $76 \pm 4$ & $56 \pm 3$ & $21.29 \pm 0.08$ \\
\hline Range & $17-22$ & $70-80$ & $54-61$ & $21.19-21.39$ \\
\hline \multicolumn{5}{|l|}{$400 \mathrm{~m}(N=6)$} \\
\hline Mean $\pm S D$ & $23 \pm 3$ & $74 \pm 9$ & $59 \pm 3$ & $47.58 \pm 1.51$ \\
\hline Range & $18-27$ & $65-91$ & $55-62$ & $45.70-49.50$ \\
\hline \multicolumn{5}{|l|}{$800 \mathrm{~m}(N=5)$} \\
\hline \multicolumn{5}{|l|}{$1500 \mathrm{~m}(N=6)$} \\
\hline Mean \pm SD & $24 \pm 3$ & $66 \pm 5$ & $72 \pm 4$ & $3: 46 \pm 0: 05$ \\
\hline Range & $21-27$ & $57-71$ & $64-75$ & $3: 39-3: 52$ \\
\hline
\end{tabular}

Experimental overview. All subjects attended two sessions at the Human Performance Laboratory at the University of Ballarat, separated by 4-7 d. To minimize any effects of diurnal variation, the two testing sessions for each athlete were conducted within $2 \mathrm{~h}$ of the same time of day. Pretest preparation included the absence of strenuous exercise and the consumption of caffeine and alcohol. All subjects documented their dietary intake for the $24 \mathrm{~h}$ proceeding the first testing session and were instructed to replicate this in the preparation for their second testing session. The subjects reported to the laboratory in a 3-h fasted state and were free to consume fluids before testing. A custom built Austradex Hercules Mark II (Melbourne, Australia) treadmill was used during the study. Due to the high treadmill velocities required to simulate 200 - to $1500-\mathrm{m}$ running, a harness body support system was used as a precautionary safety measure. Expired gases were analyzed during all tests using an automated on-line metabolic analysis system (Sensor Medics $\mathrm{V}_{\max } 29$ series, Yorba Linda, CA), in the breath by breath mode. The Sensor Medics Paramagnetic $\mathrm{O}_{2}$ Analyzer (accuracy $\pm 0.02 \% \mathrm{O}_{2}$; response time $<130 \mathrm{~ms}$ ) and NonDispersive Infrared $\mathrm{CO}_{2}$ analyzer (accuracy $\pm 0.02 \%$ $\mathrm{CO}_{2}$; response time $<130 \mathrm{~ms}$ ) were calibrated before and after each test by using two precision reference gases of known concentrations. Pulmonary ventilation was measured using a Sensor Medics Mass Flow Sensor and was calibrated before and after each test with a standard 3-L syringe.

Submaximal oxygen uptake and $\mathrm{V}_{2}$ peak determination. The first testing session involved a series of submaximal discontinuous treadmill runs $(N=5-6)$ that were of 6-min duration. Steady state $\mathrm{V}_{2}$ was determined by averaging the $\mathrm{VO}_{2}$ during the last 2 min of each submaximal run. The relative intensity of the treadmill runs ranged between $48 \pm 7 \%$ and $85 \pm 10 \% \dot{\mathrm{VO}}_{2}$ peak and was separated by rest periods increasing progressively from 5 to $9 \mathrm{~min}$. The linear relationship between steady state $\mathrm{V}_{2}$ and treadmill velocity was extrapolated and used to estimate energy demand, or $\mathrm{O}_{2}$ cost, during supramaximal treadmill exercise. Based on the findings of Jones and Doust (13), a treadmill gradient of $1 \%$ was used to reflect the energy cost of outdoor running. After approximately 20-min rest, $\dot{\mathrm{VO}}_{2}$ peak was determined via a progressive incremental protocol that involved increasing treadmill velocity $1 \mathrm{~km} \cdot \mathrm{h}^{-1} \cdot \mathrm{min}^{-1}$ for $6 \mathrm{~min}$, followed by increasing treadmill gradient $2 \% \cdot \min ^{-1}$ until volitional exhaustion. Final treadmill veloc- ities and gradients varied between the four groups, ranging from $16 \mathrm{~km} \cdot \mathrm{h}^{-1}$ and $2 \%$ for the 200 -m group (initially 10 $\mathrm{km} \cdot \mathrm{h}^{-1}$ and zero gradient) to $20 \mathrm{~km} \cdot \mathrm{h}^{-1}$ and $8 \%$ for the 1500-m group (initially $14 \mathrm{~km} \cdot \mathrm{h}^{-1}$ and zero gradient).

Supramaximal test. The second testing session involved one specific event simulation on the treadmill (either $200,400,800$, or $1500 \mathrm{~m}$ ). Before the event simulation, athletes completed their typical prerace warm-up in an attempt to simulate competition conditions. Individual times for the specific event simulation were based on race times in the previous 1-3 wk. Athletes stepped on to a moving treadmill, with the required velocity being achieved within a few seconds of the commencement of the trial. Changes in running velocity (i.e., rate of acceleration and deceleration) during the race simulations were individualized, due to different race strategies preferred by the athletes. Individualization of running velocity changes, despite being relatively minor, was of greater importance during the longer distances of 800 and $1500 \mathrm{~m}$. As the 800- and 1500-m events are run at an intensity that is relatively less than the 200- and 400-m events, the variation in preferred race strategies appears to be greater. For example, 800- and 1500-m athletes from an endurance training background usually prefer to run an even paced race, whereas athletes from a speed training background usually prefer to run a slower initial pace then exploit their speed during the final $400 \mathrm{~m}$. Although the differences in energy system contribution during varying race strategies for the selected running events have not been specifically investigated, no differences in maximal accumulated oxygen deficit (AOD) have been reported during exhaustive constant intensity and all-out cycle exercise (8).

Calculations. The AOD was defined as the difference between the estimated $\mathrm{O}_{2}$ cost of the supramaximal treadmill run and the actual $\dot{\mathrm{VO}}_{2}$ (21). The $\mathrm{O}_{2}$ cost of the supramaximal treadmill runs were calculated using the mean running velocity for each subject. Before the commencement of the present study, reliability data for AOD estimation were collected using the same methodological procedures on a group of physically active male subjects $(N=7)$. Five subjects completed a 400-m exhaustive run, with one subject each completing an 800- and 1500-m. The calculated technical error of measurement of the AOD was $6.1 \%$. Relative aerobic and anaerobic energy system contribution was calculated directly from the re- 
TABLE 2. Oxygen deficit, aerobic metabolism, and other calculated variables of the 200-, 400-, 800-, and 1500-m simulated running events,

\begin{tabular}{|c|c|c|c|c|}
\hline & $200 \mathrm{~m}$ & $400 \mathrm{~m}$ & $800 \mathrm{~m}$ & $1500 \mathrm{~m}$ \\
\hline $\begin{array}{l}\text { Exercise intensity }\left(\% \mathrm{~V}_{2} \text { peak) }\right. \\
\text { Duration (min:s) } \\
\text { Accumulated oxygen deficit }\left(\mathrm{mL} \cdot \mathrm{kg}^{-1}\right) \\
\text { Aerobic metabolism }(\%) \\
\text { Aerobic energy release first } 20 \mathrm{~s}\left(\mathrm{~mL} \cdot \mathrm{kg}^{-1}\right) \\
\text { Anaerobic energy release first } 20 \mathrm{~s}\left(\mathrm{~mL}^{-1} \mathrm{~kg}^{-1}\right) \\
\text { Regression line slope }\left(\mathrm{mL} \cdot \mathrm{kg}^{-1} \cdot \mathrm{min}^{-1}\right) \\
\% \mathrm{VO}_{2} \text { peak obtained }(\%)\end{array}$ & $\begin{aligned} 201 & \pm 3^{a b c} \\
22.3 & \pm 0.2^{a b c} \\
30.4 & \pm 3.2^{a b c} \\
29 & \pm 5^{a b c} \\
12.9 & \pm 2.0^{a b} \\
24.6 & \pm 3.6^{a b c} \\
0.349 & \pm 0.014^{a b} \\
70 & \pm 8^{a b c}\end{aligned}$ & $\begin{aligned} 151 & \pm 4^{d e} \\
49.3 & \pm 0.2^{d e} \\
41.3 & \pm 2.3^{d e} \\
43 & \pm 2^{d e} \\
9.5 & \pm 1.2^{e} \\
20.2 & \pm 1.6^{d e} \\
0.294 & \pm 0.013^{e} \\
89 & \pm 1^{e}\end{aligned}$ & $\begin{aligned} 113 & \pm 9^{f} \\
1: 53 & \pm 0: 02^{f} \\
48.8 & \pm 10.1 \\
66 & \pm 4^{f} \\
10.0 & \pm 1.6^{f} \\
15.3 & \pm 3.6^{f} \\
0.303 & \pm 0.013^{f} \\
88 & \pm 2^{f}\end{aligned}$ & $\begin{aligned} 103 & \pm 6 \\
3: 55 & \pm 0: 03 \\
47.1 & \pm 9.2 \\
84 & \pm 3 \\
14.6 & \pm 2.4 \\
10.1 & \pm 1.7 \\
0.344 & \pm 0.022 \\
94 & \pm 2\end{aligned}$ \\
\hline
\end{tabular}

Values are mean \pm SD.

Large effect size between groups (ES > 0.8); ${ }^{a} 200 \mathrm{~m}$ vs $400 \mathrm{~m} ;{ }^{b} 200 \mathrm{~m}$ vs $800 \mathrm{~m} ;{ }^{c} 200 \mathrm{~m}$ vs $1500 \mathrm{~m} ;{ }^{d} 400 \mathrm{~m}$ vs $800 \mathrm{~m} ;{ }^{e} 400 \mathrm{~m}$ vs $1500 \mathrm{~m} ;{ }^{f} 800 \mathrm{~m}$ vs $1500 \mathrm{~m}$.

search data, although no correction was made for the contribution of stored $\mathrm{VO}_{2}$. Individual running economy was established using linear regression from the relationship between steady state $\mathrm{V}_{2}$ and treadmill speed during five to six submaximal treadmill runs (Delta Graph 3.5, Delta Point, CA). Data obtained during supramaximal treadmill running (i.e., event simulation) were averaged over 10-s time intervals and the $\mathrm{O}_{2}$ deficit was accumulated with time.

Statistics. Group comparisons were investigated via the effect size, which is a method of comparing treatment effects, independent of sample size. Cohen (2) suggested the most meaningful analyses for comparing data obtained from small, uneven groups may be via effect size calculations, as the use of standard ANOVA procedures may increase the chance of producing type 1 statistical errors. Cohen (2) indicated that effect size values of $<0.2$ represent small differences, approximately 0.5 represent moderate differences, and 0.8 and above represent large treatment differences. The effect size formula is listed below:

Effect size $=\left[(m\right.$ G1 $-m$ G2) $] /\left[\sqrt{ }\left(\left(\mathrm{SD}^{2} \mathrm{G} 1\right)(\mathrm{n}-1 \mathrm{G} 1)\right.\right.$

$$
\left.+\left(\mathrm{SD}^{2} \mathrm{G} 2\right)(\mathrm{n}-1 \mathrm{G} 2) /(\mathrm{n} \mathrm{G} 1+\mathrm{n} \mathrm{G} 2-2)\right)
$$

where $\mathrm{G} 1=$ group one, $\mathrm{m}=$ group mean, $\mathrm{SD}=$ standard deviation, $N=$ group subject size.

In relation to the present study, group differences were acknowledged if a large effect size was reported (effect size $\geq 0.8$ ). Data are reported as mean $\pm \mathrm{SD}$.

\section{RESULTS}

The contribution of aerobic metabolism increased with event duration, as differences were evident between all events (Table 2). The total relative contribution of the aerobic energy system for the 200-, 400-, 800-, and 1500-m events were $29,43,66$, and $84 \%$, respectively. It is evident that the aerobic energy system responds quickly to the demands of all four events (Fig. 1), with the crossover to predominantly aerobic energy supply occurring between 15 and $30 \mathrm{~s}$ for the 400-, 800-, and 1500-m groups.

Figure 2 depicts the aerobic and anaerobic energy system contributions to each of the simulated sprint and middle distance running events. The $1500 \mathrm{~m}$ is characterized by the oxygen uptake reaching a high $\% \mathrm{VO}_{2}$ peak $(94 \%)$ and an early crossover to predominantly aerobic energy supply
(Fig. 1). Although the $\% \mathrm{VO}_{2}$ peak reached in the $200 \mathrm{~m}$ $(70 \%)$ is considerably less than in the other groups, the rate of aerobic energy release in the initial $20 \mathrm{~s}$ of exercise is similar to $1500 \mathrm{~m}$ and greater than both 400 and $800 \mathrm{~m}$ (Table 2).

The exercise intensity (\% $\dot{\mathrm{VO}}_{2}$ peak) was significantly different between all four running events and was inversely related to event duration (Table 2). The total $\mathrm{O}_{2}$ cost $\left(\mathrm{mL} \cdot \mathrm{kg}^{-1}\right)$ increased with event distance. The majority of this increased $\mathrm{O}_{2}$ cost was supplied by the aerobic energy system (Fig. 3). The size of the AOD increased with event duration except for the comparison between the 800- and 1500-m trials (Table 2; effect size $=0.29$ ). Therefore, the
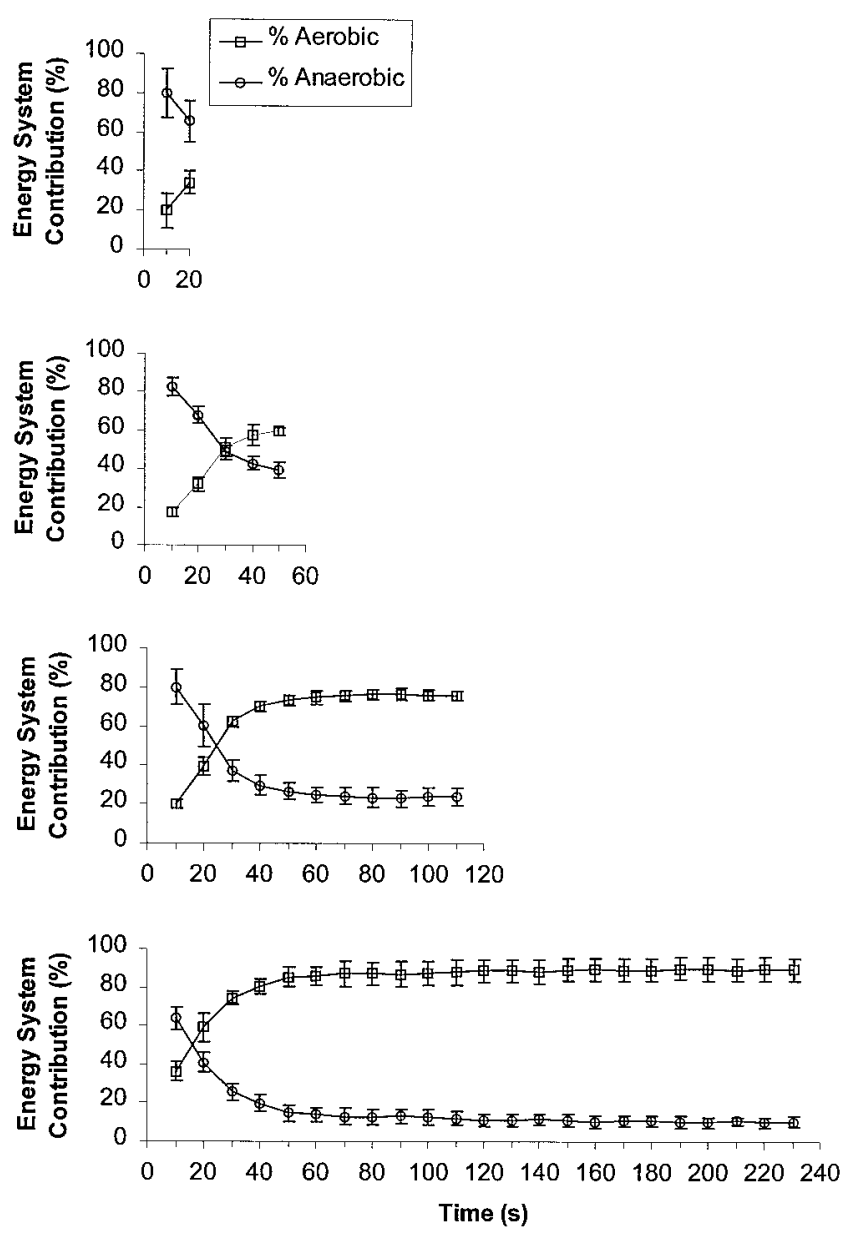

FIGURE 1-Energy system contribution in 10-s time intervals for the 200, 400, 800, and $1500 \mathrm{~m}$. Data are mean values \pm SD. 

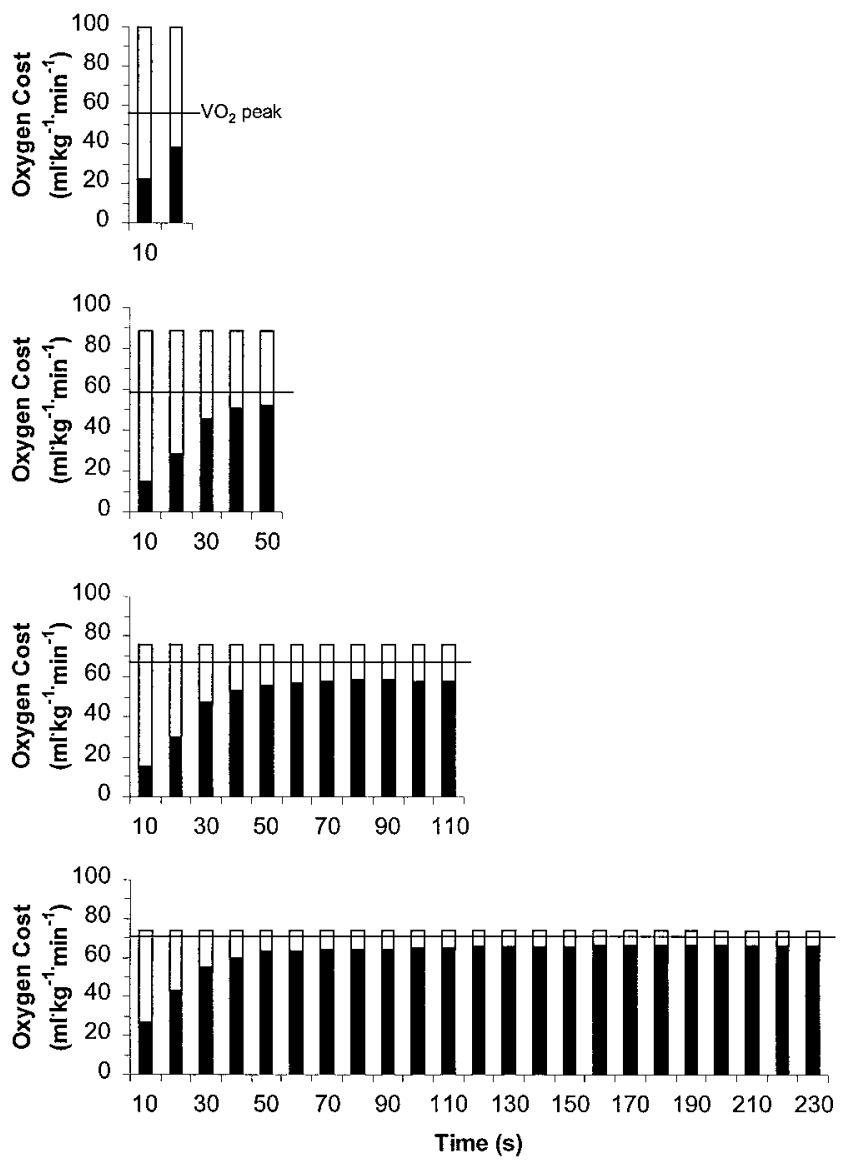

FIGURE 2-Oxygen deficit and oxygen uptake in 10-s time intervals for the 200, 400, 800, and $1500 \mathrm{~m}$. Data are mean values.

difference in event duration between the $800 \mathrm{~m}(112.8 \mathrm{~s})$ and $1500 \mathrm{~m} \mathrm{(234.5} \mathrm{s)} \mathrm{had} \mathrm{no} \mathrm{influence} \mathrm{on} \mathrm{the} \mathrm{total} \mathrm{anaerobic}$ energy release.

The initial measurements of $\mathrm{O}_{2}$ uptake and calculated $\mathrm{O}_{2}$ deficit in 10-s time intervals, for the first 20-30 s of each event, are presented in Fig. 4. The calculated $\mathrm{O}_{2}$ deficits were different between all four events at each time interval. In contrast, the rate of $\mathrm{O}_{2}$ uptake was not directly related to event intensity. The 400-m and 800-m events showed similar rates of $\mathrm{O}_{2}$ uptake. Both the $200 \mathrm{~m}$ and $1500 \mathrm{~m} \mathrm{had}$ greater rates of $\mathrm{O}_{2}$ uptake than the $400 \mathrm{~m}$ and $800 \mathrm{~m}$. No differences were observed in the rate of $\mathrm{O}_{2}$ uptake between the $200-\mathrm{m}$ and $1500-\mathrm{m}$ events at either the $10-$ or $20-\mathrm{s}$ time points, although moderate effect size were found ( 0.72 and 0.79 , respectively).

\section{DISCUSSION}

The principal finding of this research was that the aerobic energy system contributes significantly to the energy supply during long sprint and middle distance running. The study was unique in that event distances were simulated on the treadmill, as opposed to a run to exhaustion at a speed approximating average velocity during a specific event. The relative aerobic and anaerobic energy system contributions of the four simulated running events compared favorably to

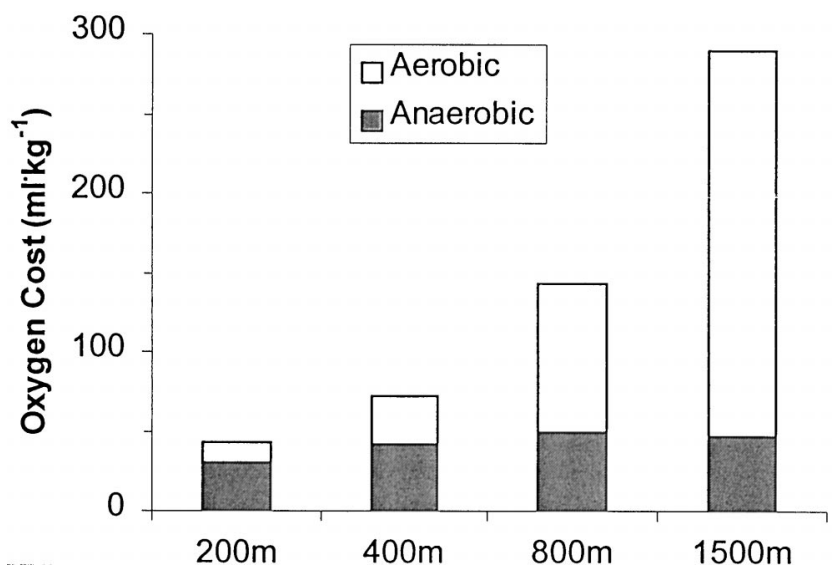

FIGURE 3-Aerobic and anaerobic contribution to the total oxygen cost of the 200-, 400-, 800-, and 1500-m runs. Data are mean values.

recent research conducted over similar time periods, during running and cycle exercise that were also exhaustive in nature. The mean aerobic contribution for the 200-m trials, which was $22 \mathrm{~s}$ in duration, was $29 \%$. This is similar to the $28-40 \%$ that has been calculated during $30 \mathrm{~s}$ of exhaustive cycling $(17,22,29)$. The $400-\mathrm{m}$ trials, which had a mean duration of $49 \mathrm{~s}$, produced an aerobic contribution of $43 \%$. These data are comparable to the $37-44 \%$ (sprint trained) and $46-50 \%$ (endurance trained) aerobic contribution seen
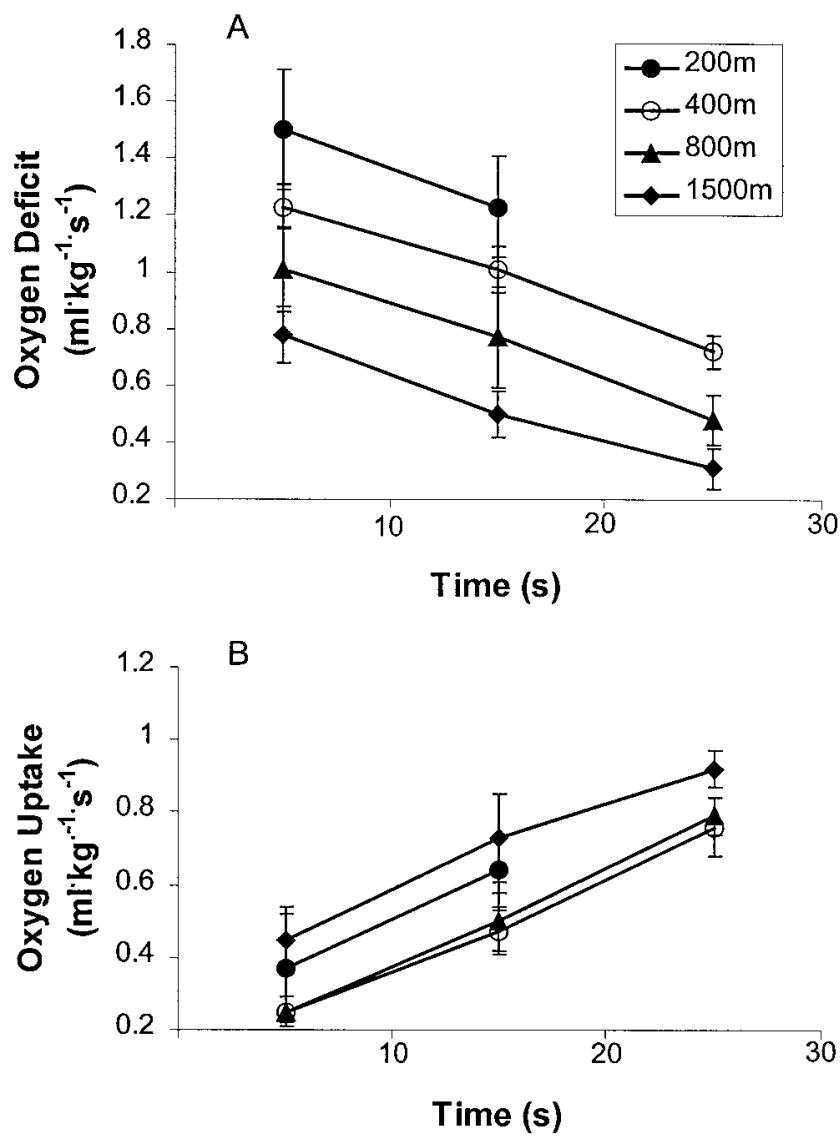

FIGURE $4-\mathrm{O}_{2}$ deficit (A) and $\mathrm{O}_{2}$ uptake (B) during the initial $30 \mathrm{~s}$ of exercise for the 200, 400, 800, and $1500 \mathrm{~m}$. Data are mean values \pm SD and are presented in 10-s time intervals. 
in $49-57 \mathrm{~s}$ of exhaustive treadmill running $(18,24)$ and the $40 \%$ aerobic contribution observed during $45 \mathrm{~s}$ of maximal cycling (29). An aerobic contribution of $66 \%$ was determined for the $800-\mathrm{m}$ simulation in the present study, with a mean duration of $113 \mathrm{~s}$. These data are similar to the $58-69 \%$ reported during $116-120 \mathrm{~s}$ of running using subelite athletes $(4,11,27)$. The $1500-\mathrm{m}$ simulation, which was $236 \mathrm{~s}$ in duration, realized an aerobic contribution of $84 \%$. These data are comparable to the $75-83 \%$ aerobic contribution reported for subelite 1500-m runners $(11,27)$.

The AODs calculated in the present study increased in relation to increasing distance and duration of the 200-, 400-, and 800-m events, but no further increase was found for the $1500-\mathrm{m}$ trials. These data support previous research which suggests the AOD is not maximal (i.e., anaerobic capacity is not attained) until a constant intensity supramaximal exercise bout of approximately 120 -s duration is completed (21). Therefore, the mean duration of the $1500-\mathrm{m}$ and possibly the $800-\mathrm{m}$ events (234 and $112 \mathrm{~s}$, respectively) were sufficient to obtain a maximal AOD. The data would suggest that the 800-m and 1500-m athletes have similar anaerobic capacities, although the possibility that the $800-\mathrm{m}$ athletes failed to obtain a maximal AOD cannot be excluded as exercise duration is slightly less than the 2 min often recommended for exhausting the anaerobic capacity (21). The calculated AODs of the middle distance athletes in the present study are similar to those reported elsewhere (26-28). Weyand et al. (28), using similar testing procedures, reported very similar AODs for a group of distance runners $\left(\mathrm{AOD}=46.8 \mathrm{~mL} \cdot \mathrm{kg}^{-1}, \dot{\mathrm{VO}}_{2}\right.$ peak $=70.9 \mathrm{~mL} \cdot \mathrm{kg}^{-}$ $\left.1 \cdot \mathrm{min}^{-1}\right)$ that were comparable to the 1500 -m group of the present study (AOD $=47.1 \mathrm{~mL} \cdot \mathrm{kg}^{-1}, \dot{\mathrm{VO}}_{2}$ peak $=71.6 \mathrm{~mL} \cdot \mathrm{kg}^{-1}$. $\left.\mathrm{min}^{-1}\right)$. Larger AODs have been reported in the literature for sprint and middle distance runners $(20,25)$. Differences in results are most likely attributable to variations in treadmill gradient, as Olesen (25) has demonstrated significantly different AODs at gradients of $1 \%\left(59.9 \mathrm{~mL} \cdot \mathrm{kg}^{-1} \cdot \mathrm{O}_{2}\right.$ equivalents $)$, $15 \%$ (78.3), and 20\% (99.8) for a group of anaerobically trained subjects.

Data from the present study and those cited in the previous paragraph were all obtained using variations of the AOD methodology developed by Medbø et al. (21). Earlier investigations that employed methodology that did not calculate individual $\dot{\mathrm{VO}}_{2}$-velocity/power relationships $(12,14)$ appear to overestimate the anaerobic energy system's contribution. Unfortunately, the findings from these studies, in which the validity of their methodologies has been questioned $(7,21)$, have formed the basis for summary material presented in the education and coaching literature from the early 1970s (15) to the mid 1990s (16). The fact that several of the world's elite 800-m running coaches have vastly different perceptions on the relative aerobic energy system contribution in their event $(35-65 \%)$ indicates the level of misconception within the sport (23).

The rate of aerobic energy release, taken as the $\mathrm{O}_{2}$ uptake during the initial $20 \mathrm{~s}$ of exercise, produced a large effect size for all comparisons except for the $200 \mathrm{~m}$ versus $1500 \mathrm{~m}$ and $400 \mathrm{~m}$ versus $800 \mathrm{~m}$ (Table 2, Fig. 4). An unexpected result from the present study was the relatively high mean aerobic energy release of the $1500-\mathrm{m}$ group $\left(0.59 \mathrm{~mL} \cdot \mathrm{kg}^{-1} \cdot \mathrm{s}^{-1}\right)$ compared with the significantly higher intensity trials of the $200-, 400-$, and $800-\mathrm{m}$ groups $(0.51,0.36$, and $0.38 \mathrm{~mL}$. $\mathrm{kg}^{-1-} \cdot \mathrm{s}^{-1}$ ). Gastin et al. (8) reported a significant increase in the rate of aerobic energy release in the same subjects exercising at higher intensities during the first $30 \mathrm{~s}$ of supramaximal cycling. Gastin (7), however, reported no differences in the rate of energy release during the first $30 \mathrm{~s}$ of a 90-s all-out bout of cycle exercise between untrained, endurance-trained, and sprint-trained subjects when expressed in relative terms $\left(\mathrm{mL} \cdot \mathrm{kg}^{-1} \cdot \mathrm{min}^{-1}\right)$. In, contrast, Nummela and Rusko (24) found that endurance-trained athletes produced a significantly higher rate of aerobic energy release than sprint-trained athletes at the 30-s time point during a 49-s bout of supramaximal treadmill running. Interestingly, the highest $\dot{\mathrm{VO}}_{2}\left(\% \dot{\mathrm{V}} \mathrm{O}_{2}\right.$ peak) obtained during the $800-\mathrm{m}$ and $1500-\mathrm{m}$ trials were quite low, 88 and $94 \%$, respectively. This may be due to differences in active muscle mass recruited during horizontal and inclined treadmill running (3) as a higher treadmill gradient was used during the $\mathrm{VO}_{2}$ peak test $(6-8 \%)$ compared with the performance runs $(1 \%)$. This finding is supported by Hermansen and Saltin (10), who reported a higher $\mathrm{VO}_{2}$ peak during exhaustive running on an inclined treadmill (5\%) compared with a horizontal treadmill $(0 \%)$ protocol of similar duration.

Previous investigations that have evaluated the relative aerobic and anaerobic energy system contributions during exhaustive exercise have been conducted over set time durations which are not specific to a sporting event $(8,21,22,29)$. To accurately profile the energy system contribution during sporting events, specifically trained athletes should be used as subjects. The training status of subjects is an important issue as Nummela and Rusko (24) calculated the relative aerobic energy system contribution during $49 \mathrm{~s}$ of exhaustive treadmill running and reported a significantly greater contribution for endurance-trained subjects compared with sprint-trained (46\% and 37\%, respectively). The present study used specifically trained athletes to profile the 200-, 400-, 800-, and 1500-m track running events in an attempt to accurately assess the energetics of these events.

The energy system profiles of the selected events may be of most value for the middle distance coach. The relative exercise intensity (\% $\mathrm{V}_{2}$ peak) of the $200,400,800$, and $1500 \mathrm{~m}$ were $201,151,113$, and $103 \%$, respectively. In terms of exercise intensity, the 800 and $1500 \mathrm{~m}$ appear to be the most closely related. This finding may help to explain the observation why many elite $800-\mathrm{m}$ runners are highly competitive over $1500 \mathrm{~m}$ rather than $400 \mathrm{~m}$ (23). The relative aerobic energy system contribution (percent of total energy demand) clearly increases in significance during the longer duration events but is considerably greater in the shorter duration events than traditionally thought $(12,14)$. This finding suggests that the role of the aerobic energy system during the $200 \mathrm{~m} \mathrm{(29 \% )}$ and especially the $400 \mathrm{~m}$ (43\%) should be acknowledged and considered when planning the training program for athletes competing in these two events. The relative interaction of the aerobic and 
anaerobic energy systems for the selected running events is presented in Figure 1. It is evident that, for all four events, the aerobic energy system contributes considerably to the initial energy demand. Furthermore, the transition from predominantly anaerobic energy supply to predominantly aerobic energy supply occurs between the 15- and 30-s time period for the 400-, 800-, and 1500-m events. If the AOD calculations had been corrected for the body's $\mathrm{O}_{2}$ stores, estimated to represent approximately $10 \%$ of the maximal AOD (21), this energy system transition may have been recorded earlier. This is supported by Medbø et al. (17), who reported the total aerobic energy system contribution (measured $\mathrm{VO}_{2}$ plus the assumed use of stored $\mathrm{O}_{2}$ ) to be $31 \%$ and $38 \%$ during exhaustive cycling of $12.5 \mathrm{~s}$ and $31 \mathrm{~s}$, respectively.

The results pertaining to anaerobic metabolism and relative energy system contribution in this study are dependent on the acceptance of the AOD as a valid method of quantifying anaerobic energy release during high intensity exercise. The AOD methodology attempts to estimate the metabolic response of the active muscles to a particular exercise

\section{REFERENCES}

1. Bangsbo, J. Oxygen deficit: a measure of the anaerobic energy production during intense exercise? Can. J. Appl. Physiol. 21: 350-363, 1996.

2. Cohen, J. Things I have learned (so far). Am. Psychol. 45:13041312, 1990.

3. Costill, D., E. Jansson, P. Gollnick, and B. Saltin. Glycogen utilisation in leg muscles of men during level and uphill running. Acta Physiol. Scand. 91:475-481, 1974.

4. Craig, I. S., and D. G. Morgan. Relationship between 800-m running performance and accumulated oxygen deficit in middle-distance runners. Med. Sci. Sports Exerc. 30):1631-1636, 1998.

5. Craig, N. P., K. I. Norton, P. C. Bourdon, et al. Aerobic and anaerobic indices contributing to track endurance cycling performance. Eur. J. Appl. Physiol. 67:150-158, 1993.

6. Gastin, P. Energetics of High Intensity Running. Mod. Athl. Coach 36(3):3-9, 1998.

7. Gastin, P. B. Quantification of anaerobic capacity. Scand. J. Sci. Med. Sports 4:91-112, 1994.

8. Gastin, P. B., D. L. Costill, D. L. Lawson, K. Krzeminski, and G. K. Mcconell. Accumulated oxygen deficit during supramaximal all out and constant intensity exercise. Med. Sci. Sports Exerc. 27:255-263, 1995.

9. Green, S., and B. T. Dawson. Methodological effects on the $\mathrm{VO}_{2}$-power regression and the accumulated $\mathrm{O}_{2}$ deficit. Med. Sci. Sports Exerc. 28:392-397, 1996.

10. Hermansen, L., and B. Saltin. Oxygen uptake during maximal treadmill and bicycle exercise. J. Appl. Physiol. 26:31-37, 1969.

11. Hill, D. W. Energy system contribution in middle-distance running events. J. Sports Sci. 17:477-483, 1999.

12. Inbar, O., R. Dotan, and O. Bar-Or. Aerobic and anaerobic components of a thirty-second supra-maximal cycling task (Abstract). Med. Sci. Sports Exerc. 8:51, 1976.

13. Jones, A. M., and J. H. Doust. A $1 \%$ treadmill grade most accurately reflects the energetic cost of outdoor running. J. Sports Sci. 14:321-327, 1996.

14. Karlsson, J., and B. Saltin. Lactate, Atp, and CP in working muscles during exhaustive exercise in man. J. Appl. Physiol. 29:598-602, 1970. bout, via the "whole body" metabolic response of expired gases. The underlying assumptions of the method are complex and difficult to prove, but have been discussed in great detail previously $(1,7,19)$. Despite theoretical concerns $(1,9)$ the method is considered a valid procedure for estimating anaerobic energy release during intense whole body exercise $(7,19,21)$.

It is concluded that the relative contribution of the aerobic energy system is considerable and greater than has been traditionally accepted during 200-, 400-, 800-, and 1500-m running. The results demonstrate that the aerobic energy system is the predominant energy system by the 30 -s time period during the 400-, 800-, and 1500-m running events.

The authors would like to acknowledge the contribution of Asst. Prof. Warren Payne during this study and earlier preliminary work. Thanks also go to Andrew Russell, Bob O'Brien, Justin Grantham, and Dr. David Bishop for their assistance. This study was funded by the Australian Sports Commission.

Address for correspondence: Matt Spencer, M.Sc., Western Australian Institute of Sport, P.O. Box 139, Claremont, WA. 6010, Australia; E-mail: mspencer@wais.org.au.

15. Mathews, D. K., and E. L. Fox. The physiological basis of physical education and athletes, 1 st Ed. Philadelphia: W. B. Saunders, 1971, p. 19.

16. Mcardle, W. D., F. I. Katch, and V. L. Katch. Exercise Physiology, Energy Nutrition and Human Performance, 4th Ed. Baltimore: Williams \& Wilkins, 1996, pp. 129-130.

17. Medbo, J., P. Gramvik, and E. Jebens. Aerobic and anaerobic energy release during 10 and $30 \mathrm{~s}$ bicycle sprints. Acta Kinesiol. Univ. Tartuensis 4:122-146, 1999.

18. Меdbø, J., and O. Sejersted. Acid-base and electrolyte balance after exhausting exercise in endurance-trained and sprint-trained subjects. Acta Physiol. Scand. 125:97-109, 1985.

19. Мedвø, J. I. Medbø responds to Bangsbo's paper. Can. J. Appl. Physiol. 21:364-369, 1996.

20. Мedbø, J. I., and S. BuRgers. Effect of training on the anaerobic capacity. Med. Sci. Sports Exerc. 22:501-507, 1990.

21. Medbø, J. I., A. C. Mohn, I. Tabata, R. Bahr, O. Vaage, and O. SEJERSTED. Anaerobic capacity determined by maximal accumulated $\mathrm{O}_{2}$ deficit. J. Appl. Physiol. 64:50-60, 1988.

22. Medbø, J. I., and I. Taвata. Relative importance of aerobic and anaerobic energy release during short-lasting exhausting bicycle exercise. J. Appl. Physiol. 67:1881-1886, 1989.

23. NSA-Round-Table. Speed in the 800 metres. New Studies Athl. 11(4):7-22, 1996.

24. Nummela, A., and H. Rusko. Time course of anaerobic and aerobic energy expenditure during short term exhaustive running in athletes. Int. J. Sports Med. 16:522-527, 1995.

25. Olesen, H. L. Accumulated oxygen deficit increases with inclination of uphill running. J. Appl. Physiol. 73:1130-1134, 1992.

26. Scott, C. B., F. B. Roby, T. G. Lothman, and J. C. Bunt. The maximally accumulated oxygen deficit as an indicator of anaerobic capacity. Med. Sci. Sports Exerc. 23:618-624, 1991.

27. Spencer, M. R., P. B. Gastin, and W. R. Payne. Energy system contribution during 400 to 1500 meters running. New Studies Athl. 11(4):59-65, 1996.

28. Weyand, P. G., K. J. Cureton, D. S. Conley, M. A. Sloniger, and Y. L. Liu. Peak oxygen deficit predicts sprint and middle-distance track performance. Med. Sci. Sports Exerc. 26:1174-1180, 1994.

29. Withers, R. T., W. M. Sherman, D. G. Clarket et al. Muscle metabolism during 30,60 , and $90 \mathrm{~s}$ of maximal cycling on an air-braked ergometer. Eur. J. Appl. Physiol. 63:354-362, 1991. 